\title{
Electromodulated infrared spectroscopy of methanol electrooxidation on electrodispersed platinum electrodes
}

\section{Enhancement of reactive intermediates}

\author{
B. Beden, F. Hahn, J.M. Léger and C. Lamy
}

Laboratoire de Chimie I, U.A. au CNRS No. 350, Université de Poitiers, 40 avenue du Recteur Pineau, 86022 Poitiers Cedex (France)

\author{
C.L. Perdriel, N.R. De Tacconi, R.O. Lezna and A.J. Arvia
}

Instituto de Investigaciones Fisicoquimicas Teoricas y Aplicadas, (INIFTA), Facultad de Ciencias Exactas, Universidad Nacional de La Plata, C/C. 16, Suc. 4, (1900) La Plata (Argentina)

(Received 16 March 1990)

\begin{abstract}
EMIRS spectra of the surface species resulting from methanol electrosorption on electrodispersed Pt were obtained by working under a wide range of experimental conditions, i.e. electrode roughness factor, methanol concentration and mean modulation potential. The intensity of the absorption band related to linearly adsorbed $\mathrm{CO}$-species, $\mathrm{CO}_{\mathrm{L}}$, at ca. $2030-2080 \mathrm{~cm}^{-1}$ decreases on increasing the electrode roughness factor, a fact which is interpreted as a decrease in the $\mathrm{CO}$ adsorbate poisoning effect on clectrodispersed Pt surfaces. As a consequence, under well-defined conditions, several bands are observed which might be assigned to adsorbed intermediates and reactive species. EMIRS also reveals a competition between $\mathrm{CO}_{\mathrm{B}}$ and $\mathrm{CO}_{\mathrm{L}}$ at high surface coverages. Spectral data for methanol electrooxidation on electrodispersed electrodes correlate well with the expected structure of this type of electrode.
\end{abstract}

\section{INTRODUCTION}

The electrooxidation of organic fuels on $\mathrm{Pt}$ has been the subject of careful investigations in order to clarify the formation and behaviour of catalytic poisons produced and accumulated progressively on the electrode surface in the course of the reaction. The application of EMIRS to study this problem has proved to be successful for identifying various $\mathrm{CO}$ adsorbates acting as inhibitors in these reactions. In this sense the adsorption of $\mathrm{CO}$ has become an extremely valuable reference to establish the difference between inhibitors and effective catalytic 
intermediates in the electrooxidation of organic fuels. Besides, recently obtained results using Pt single crystals [1-3], Pt preferred crystalline oriented electrodes (pco) [4,5], and Pt electrodispersed electrodes [4] yielded valuable information on the influence of crystalline structure, surface texture and grain size on the distribution of poisoning and/or reactive intermediates in the course of the electrooxidation of organic fuels.

This work aims to detect the different intermediates, i.e. poisons and reactive intermediates, taking part in the electrochemical oxidation of methanol in acid solutions on electrodispersed Pt electrodes, and to distinguish between poisoning and reactive intermediates in the process. This discrimination is particularly useful for advancing the mechanistic interpretation of electrocatalysis and for encouraging further work on the behaviour of reactive intermediates through the application of in situ surface spectroscopy on carefully prepared electrode surfaces.

\section{EXPERIMENTAL}

The electrodispersed Pt electrodes were prepared using a two stage procedure [6]. The initial step consists in the formation of a hydrous platinum oxide layer of a given thickness by applying a $5 \mathrm{kHz}$ square wave perturbing potential between 0.0 and $2.4 \mathrm{~V}$ (vs. RIIE), for times ranging from $10 \mathrm{~s}$ to $2 \mathrm{~min}$. The second stage is the electroreduction of the oxide layer by means of a single potential scan from $0.7 \mathrm{~V}$ down to $0.0 \mathrm{~V}$ at $2 \mathrm{mV} / \mathrm{s}$. The electrodispersed $\mathrm{Pt}$ electrode is then rinsed repeatedly in Millipore water before being placed in the EMIRS cell. The electrolytic solutions were prepared from $\mathrm{HClO}_{4}$ (Merck suprapur), $\mathrm{CH}_{3} \mathrm{OH}$ (Merck pa), and Millipore Milli $Q$ water.

Voltammetry and EMIR spectroscopy measurements were made at $25^{\circ} \mathrm{C}$ following the procedures described in previous publications [1,2,4]. The areas of the electrodispersed $\mathrm{Pt}$ electrodes were evaluated using the $\mathrm{H}$-atom electrosorption charge. The roughness factor, $R F$, was defined as an operational magnitude given by the ratio of the real electrode area, $A_{\text {real }}$, as determined by integration of the voltammetric curves of $\mathrm{H}$-atom electroadsorption, and the geometric area, $A_{\text {geom }}$, that is, $R F=A_{\text {real }} / A_{\text {geom }}$. Thus, $R F$ was made to range from 4 to 50 .

\section{RESULTS AND INTERPRETATION}

\section{Voltammetric data}

The voltammogram of an electrodispersed $\mathrm{Pt}$ electrode, with $R F=18$, in $1 \mathrm{M}$ $\mathrm{HClO}_{4}$ from 0.0 to $1.4 \mathrm{~V}$ at $0.1 \mathrm{~V} / \mathrm{s}$ (Fig. 1a) shows the well-known $\mathrm{H}$-atom and O-atom electroadsorption/electrodesorption complementary peaks.

The voltammogram run under comparable conditions at $0.05 \mathrm{~V} / \mathrm{s}$ in $0.5 \mathrm{M}$ $\mathrm{HClO}_{4}+0.1 \mathrm{M} \mathrm{CH}_{3} \mathrm{OH}$ (Fig. 1b) displays a wide peak at $0.85 \mathrm{~V}$ on the positive scan associated with methanol electrooxidation, followed by another process from $1.05 \mathrm{~V}$ upwards which inhibits the methanol electrooxidation reaction during the reverse scan in the $1.3 \mathrm{~V}$ to ca. $0.8 \mathrm{~V}$ range. However, at lower potentials, on the same scan, a net reactivation of the electrooxidation can be observed characterised 


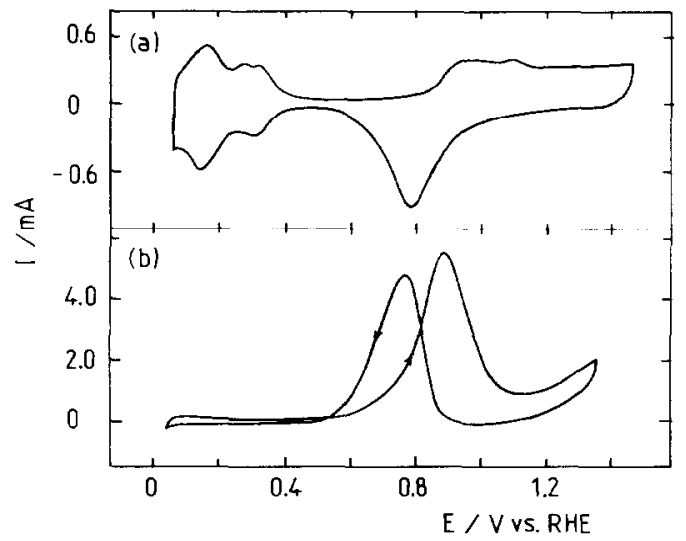

Fig. 1. Voltammograms of an electrodispersed $\mathrm{Pt}$ electrode $(R F=18)$ at $25^{\circ} \mathrm{C}$. (a) $1 \mathrm{M} \mathrm{HClO}_{4}, v=100$ $\mathrm{mV} \mathrm{s}^{-1}$; (b) $0.5 \mathrm{M} \mathrm{HClO}_{4}+0.1 \mathrm{M} \mathrm{CH}_{3} \mathrm{OH}, v=50 \mathrm{mV} \mathrm{s}^{-1}$.

by a broad current peak centered at $0.72 \mathrm{~V}$. As a result of the further methanol readsorption, the charge corresponding to $\mathrm{H}$-atom electroadsorption becomes negligible.

\section{Spectroscopic data}

The EMIRS spectra shown in Fig. 2 were obtained by averaging 5 scans, with an electrodispersed Pt electrode of $R F=18$, in $0.5 \mathrm{M} \mathrm{HClO}_{4}+0.1 \mathrm{M} \mathrm{CH}_{3} \mathrm{OH}$, at 13.5 $\mathrm{Hz}$ and $0.2 \mathrm{~V}$ amplitude centered at a mean potential $\bar{E}$, which, in turn, was varied from $0.1 \mathrm{~V}$ to $0.6 \mathrm{~V}$ vs. RHE. All the spectra were smoothed (solid lines on the figures), but original non-smoothed data are also presented (dashed lines), to appreciate the reduction of noise level by data processing. It is clear that the noise level is more critical in the region of water absorption $\left(1600-1700 \mathrm{~cm}^{-1}\right)$.

Several bands can be observed within the $1600-2350 \mathrm{~cm}^{-1}$ spectral range, with their relative contributions changing according to the $\bar{E}$ value. The change in intensity of the bands can be attributed to a change in the concentration ratio of the different adsorbates. EMIRS is known to give various types of bands $[7,8]$, such as monopolar, bipolar with either symmetric or different lobe contributions, depending on the intensity and frequency at which the species responsible for the band are absorbing at the modulation potential limits.

For $\bar{E}=0.2 \mathrm{~V}$, the Pt surface is known not to be covered completely by $\mathrm{CO}$ adsorbates, particularly with smooth electrodes [9], thus allowing different species to adsorb. It is at this potential that a comparatively intense response in $\Delta R / R$, although rather complex, can be detected in the $1600-1750 \mathrm{~cm}^{-1}$ region. Classically, the bending mode of water is supposed to absorb in the range 1600-1650 $\mathrm{cm}^{-1}$, while the bands in the domain $1650-1750 \mathrm{~cm}^{-1}$ have been tentatively assigned to $\cdot \mathrm{CHO}$ and/or $\cdot \mathrm{COOH}$ species, on the basis of the literature for the carbonyl stretching modes $[9,10]$. In the $1780-1900 \mathrm{~cm}^{-1}$ region, multibonded $\mathrm{CO}$ 


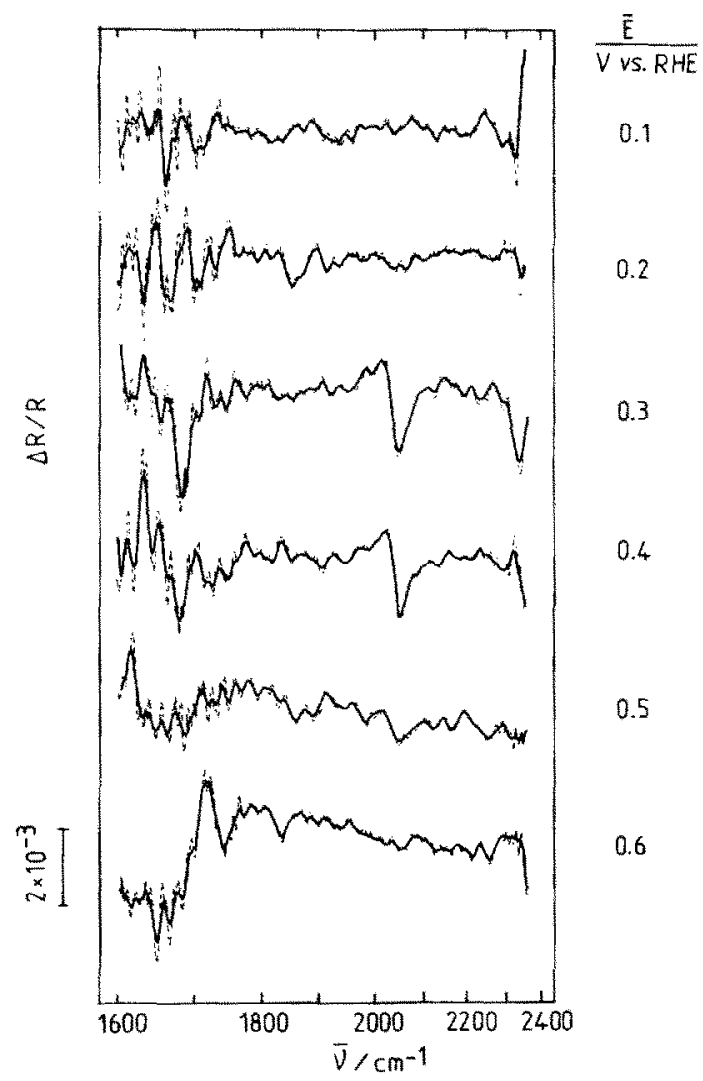

Fig. 2. EMIRS spectra of the adsorbed species produced during the chemisorption of $0.1 \mathrm{M}$ methanol in $0.5 \mathrm{M} \mathrm{HClO}_{4}$ at the electrodispersed $P t$ electrode for $\bar{E}$ ranging from $0.1 \mathrm{~V}$ to $0.6 \mathrm{~V}$ vs. RHE. $R F=18$, $\Delta E=200 \mathrm{mV}, f=13.5 \mathrm{~Hz}, 5$ scans. Solid lines: smoothed data.

adsorbates eventually absorb, so that the weak, but clear band at $1860 \mathrm{~cm}^{-1}$, which was hardly seen at slightly lower wavenumbers when the mean potential was $0.1 \mathrm{~V}$, could be assigned to $\mathrm{CO}_{\mathrm{m}}$, in agreement with the now well-established fact that multibonded $\mathrm{CO}$ absorbed species are the precursor state for linearly bonded $\mathrm{CO}$.

On the other hand, for $\bar{E}=0.3 \mathrm{~V}$, the coverage of a smooth Pt electrode surface by $\mathrm{CO}$ species is nearly complete [9]. Similarly, with rough surfaces, a bipolar band corresponding to linearly bonded $\mathrm{CO}$ species is seen clearly in the spectrum at $2020-2040 \mathrm{~cm}^{-1}$, i.e. at slightly lower wavenumbers than on smooth Pt [11]. This band displays a positive lobe, arising from absorption at the lower potential limit of the modulation. The positive lobe becomes broader in width and of lesser intensity than its negative counterpart, which corresponds to more radiation absorption at the upper potential limit of the modulation. The band can still be detected at $\bar{E}=0.4 \mathrm{~V}$ and at $\bar{E}=0.5 \mathrm{~V}$, although with a decreasing intensity as $\bar{E}$ is made more positive. 
For $\bar{E}=0.6 \mathrm{~V}$ the band is no longer seen, whereas the absorption band attributed to multibonded CO reappears in the spectrum at ca. $1840 \mathrm{~cm}^{-1}$.

At $\bar{E}=0.6 \mathrm{~V}$, a complex band with two contributions, the first one, intense, with a negative lobe at $\bar{\nu}<1700 \mathrm{~cm}^{-1}$ and a clear positive lobe at $1720 \mathrm{~cm}^{-1}$, and the second one, weaker, having its two lobes at 1730 and $1760 \mathrm{~cm}^{-1}$, are shown in this spectrum. Taking into account the positive limit of the modulating signal, the latter band can be attributed to $\mathrm{C}=\mathrm{O}$ stretching vibrations of $\cdot \mathrm{COOH}$ groups, engaged either in intermediates, or in adsorbed reaction products, while the former is probably associated with $\cdot$ CHO groups (reactive species). Somewhat similar bands were recently detected by SNIFTIRS at potentials where methanol oxidation takes place [12]. However, the contribution of the $\mathrm{C}=\mathrm{O}$ stretching mode of adsorbed methyl formate could also be invoked since the presence of this species in solution has been detected during the electrolysis of methanol $[13,14]$.
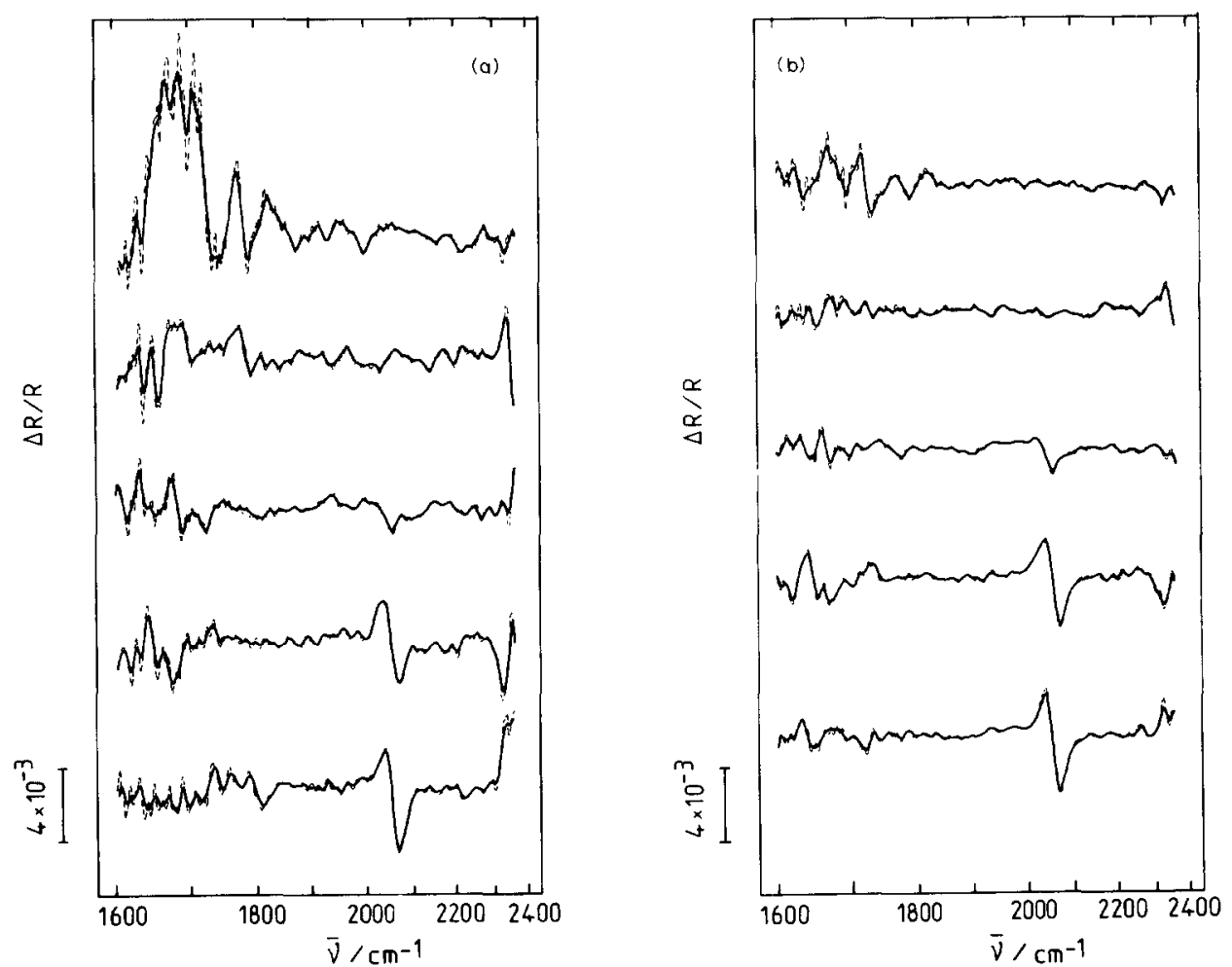

Fig. 3. EMIRS spectra of the adsorbed species produced during the chemisorption of methanol in $0.5 \mathrm{M}$ $\mathrm{HClO}_{4}$ at the electrodispersed $\mathrm{Pt}$ electrode. Methanol concentration from top to bottom: $10^{-3}, 10^{-2}$, $10^{-1}, 5 \times 10^{-1}$ and $1 \mathrm{M} . R F=26, \Delta E=200 \mathrm{mV}, \bar{E}=0.3 \mathrm{~V}$ vs. RHE. (a) 1 single scan; (b) 5 averaged scans. Solid lines: smoothed data. 


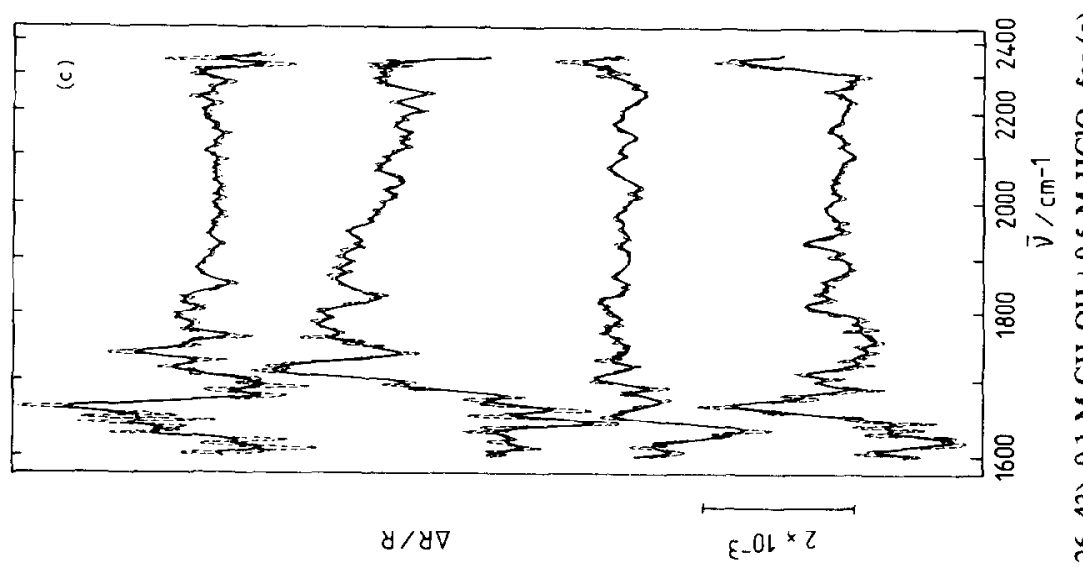

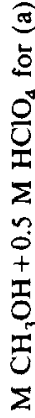

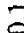

宇

i

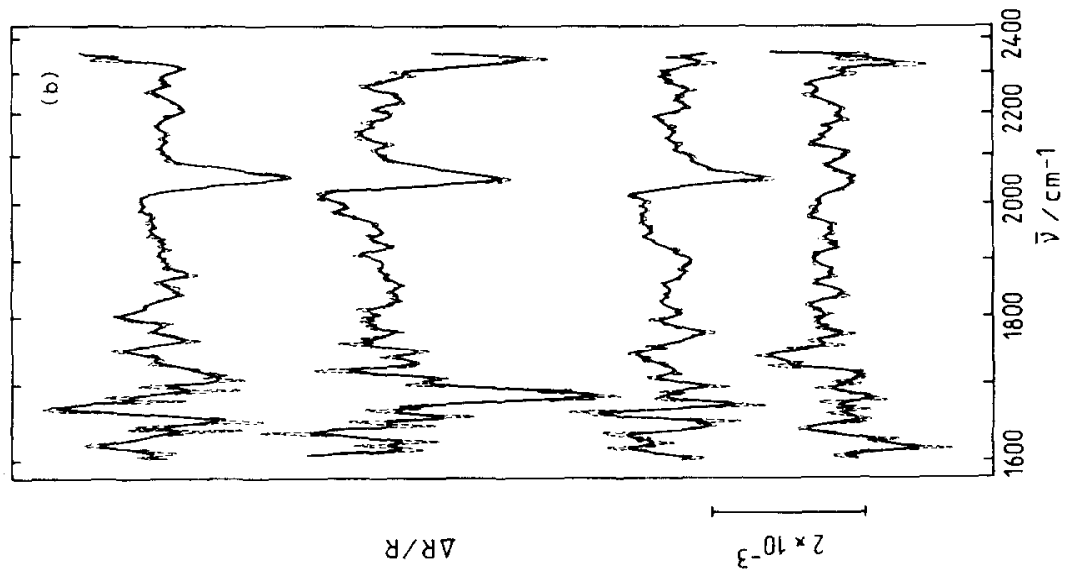

$\infty$

ri

घี

5

용

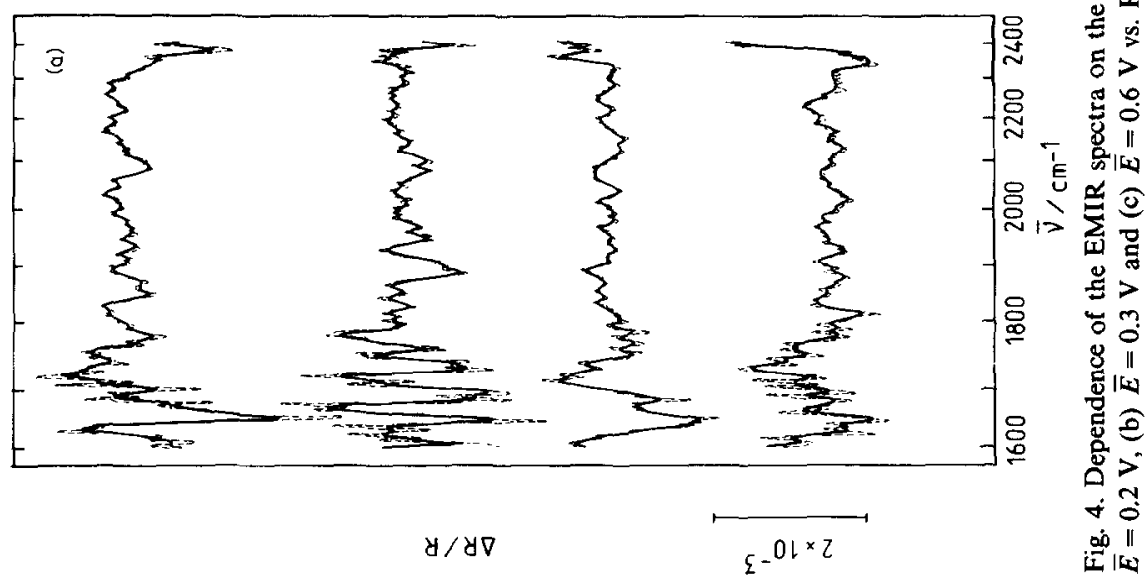


Influence of methanol concentration and adsorption time on EMIR spectra

The influence of methanol concentration on the distribution and intensity of the EMIRS bands, in the $10^{-3} \mathrm{M}$ to $1 \mathrm{M}$ range, has been studied, using a single spectral scan (Fig. 3a) or five averaged scans (Fig. 3b), on a Pt electrodispersed electrode with $R F=26$. The $\bar{E}$ value for both experiments was set to $0.3 \mathrm{~V}$, so as to attain a nearly complete coverage of the electrode surface by adsorbates. These results can be used to compare, for a given methanol concentration, the evolution of the bands on rough $P t$ surfaces with the averaging time, i.e. with the adsorption time.

The main features deduced from Fig. 3 can be described as follows:

(i) The band in the $1640-1700 \mathrm{~cm}^{-1}$ range can be observed for the lowest methanol concentration particularly with a single scan; i.e. at short adsorption times. Its appearance is apparently restricted to the low concentrations of methanol. This behaviour is in agreement with previous EMIRS data already reported for smooth Pt electrodes [9]. Besides this very intense band, a smaller one at ca. 1780 $\mathrm{cm}^{-1}$, similar to the band described in the previous section, is also detected at low methanol concentrations. $\mathrm{CO}$ bands, with very weak intensities, are hardly seen.

(ii) The decrease in the poisoning effect for rough electrodes, as measured by the intensity of the $\mathrm{CO}_{L}$ band, can be inferred through the comparison of the spectra in Fig. 3 with those already obtained with a smooth $\mathrm{Pt}$ electrode under similar experimental conditions [9]. Moreover, the increase in intensity of the $\mathrm{CO}_{\mathrm{L}}$ band with concentration of methanol is also a common feature to rough and smooth polycrystalline $\mathrm{Pt}$ electrodes.

(iii) For methanol concentrations lower than $10^{-1} \mathrm{M}$, the $\mathrm{CO}_{\mathrm{L}}$ absorption band is not appreciably detected, even for five averaged scans, and in spite of the fact that for the selected value of $\bar{E}$, a maximum contribution of $\mathrm{CO}_{\mathrm{L}}$ adsorbed species should be expected (by comparison with smooth $\mathrm{Pt}$ ). The band assignment is summarized as follows.

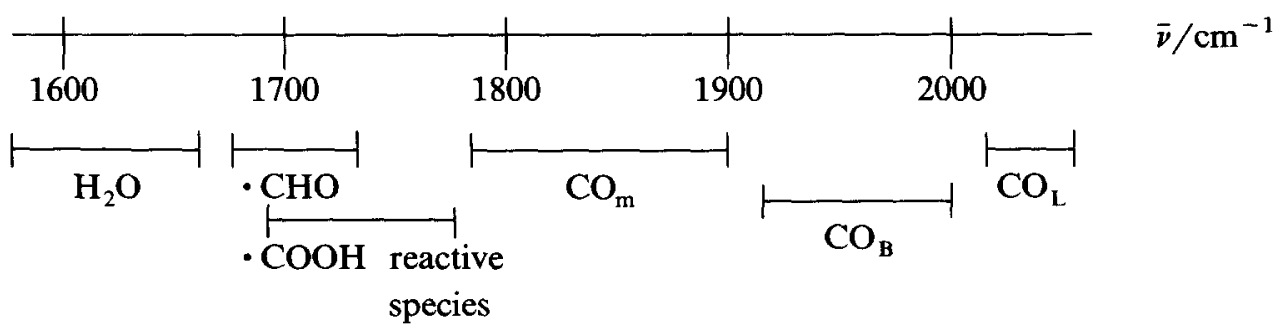

Influence of the roughness factor of electrodispersed platinum

Figure 4 shows EMIRS spectra taken with electrodes of various roughness factors ( $R F$ ) ranging from 7 to 43 and for three different values of $\bar{E}$, other conditions being equal. At $\bar{E}=0.2 \mathrm{~V}$ (Fig. 4a) the surface is only partially covered by the species on the electrode. Under these conditions the $\mathrm{CO}_{\mathrm{L}}$ band is barely distinguishable, whereas the band at ca. $1780 \mathrm{~cm}^{-1}$ appears with the highest intensity for the lowest value of $R F$. 
For $\bar{E}=0.3 \mathrm{~V}$ (Fig. 4b) the maximum coverage for adsorbed $\mathrm{CO}$ is normally attained [9]. Under these conditions the spectra indicate clearly that the intensity of the $\mathrm{CO}_{\mathrm{L}}$ band decreases with increasing $R F$. This is probably the most important feature of electrodispersed $\mathrm{Pt}$ electrodes. Besides, the $\mathrm{CO}_{\mathrm{L}}$ band is non-symmetrical for $R F=7$, whilst it becomes symmetrical for $R F=18$, then decreases so strongly than it is hardly visible at $R F=43$. This evolution means that the amount of $\mathrm{CO}_{\mathrm{L}}$ species at the positive limit of the modulation diminishes as $R F$ is increased. On the other hand, a band arising from $\mathrm{CO}_{\mathrm{B}}$ species begins to show up for values of $R F$ larger than 18, leading to a wide positive shoulder extending from ca. 1920 to 2000 $\mathrm{cm}^{-1}$ at $R F=26$. At the same time the intensity of the $\mathrm{CO}_{\mathrm{L}}$ band is attenuated. Thus the competition between the two distinguishable $\mathrm{CO}$ adsorbates is to be expected at high surface coverages. On the other hand, the infrared signal in the $1600-1700 \mathrm{~cm}^{-1}$ spectral region diminishes with $R F$, although to a minor extent as compared to the decrease in the intensity of the $\mathrm{CO}_{\mathrm{L}}$ band. Finally, for $R F=43$ the noisy EMIRS bands resulting from electrodispersed $\mathrm{Pt}$ involve most probably the three types of $\mathrm{CO}$ which have been discussed in preceding publications, i.e. $\mathrm{CO}_{\mathrm{m}}$, $\mathrm{CO}_{\mathrm{B}}$ and $\mathrm{CO}_{\mathrm{L}}[15]$.

For $\bar{E}=0.6 \mathrm{~V}$ (Fig. $4 \mathrm{c}$ ), the coverage by the $\mathrm{CO}$ adsorbate cannot be attained because of the onset of the adsorbate electrooxidation process. Under these conditions the $\mathrm{CO}_{\mathrm{L}}$ band is practically absent in the spectra, whereas the double complex band is again observed in the $1640-1800 \mathrm{~cm}^{-1}$ spectral range besides the $\mathrm{CO}_{\mathrm{m}}$ band. It is worth noting that the double complex band can only be measured at high modulation potentials where the adsorbate is being partially oxidised. The spectral features observed in the $1600-1680 \mathrm{~cm}^{-1}$ range, which become more relevant in electrodispersed Pt electrodes, can be associated to an increase in the concentration of reactive intermediates directly related to methanol electrooxidation at the electrocatalyst surface.

\section{CONCLUSIONS}

The fact that electrodispersed $\mathrm{Pt}$ electrodes behave more actively for the electrocatalytic oxidation of methanol, as deduced from the modifications of the EMIRS spectra observed by changing the electrode roughness factor and the methanol concentration, is in agreement with previously reported voltammetric data on reduced $\mathrm{CO}_{2}$ [16] and adsorbed $\mathrm{CO}$ electrooxidation in acid solution [17] on this type of electrode. The increase in the electrocatalytic activity of electrodispersed $\mathrm{Pt}$ electrodes has to be related to the proper structure and roughness geometry of the $\mathrm{Pt}$ metal overlayer resulting from the electroreduction of thick hydrous $\mathrm{Pt}$ oxide layers.

According to recent ex-situ scanning tunneling microscopy (STM) and scanning electron microscopy (SEM) combined with STM images, the rough structure of the electrodispersed $\mathrm{Pt}$ overlayer involves a piling up of Pt clusters of about $10 \mathrm{~nm}$ average diameter ordered in a brush-like-structure [18,19]. It is reasonable to relate the catalytic activity of these electrodes to the way the different crystallographic 
sites on metal clusters vary with particle size and structure. There is evidence that very small microcrystals can possess a structure unlike that expected for the macroscopic material $[20,21]$. Thus, fcc metals such as $\mathbf{P t}$ in the shape of very small particles with an icosahedral structure may have a surface primarily consisting of triangular (111) faces. Although it is unrealistic to expect that the electrodispersed Pt contains particles with the exact structure of geometric models, it should be noticed, however, that for this type of electrode the development of (111) faces has been deduced from X-ray diffractometry [22].

On the other hand, the adsorption of CO from the gas phase on unsupported and supported $\mathrm{Pt}$ catalysts at room temperature is known to take place on two types of sites: terrace (closed packed) and step (open) sites [23-26], CO being more tightly bound on the former.

Therefore, the electrocatalytic characteristics of electrodispersed Pt electrodes, as confirmed through the EMIRS spectra related to methanol electrooxidation, have to be thought of in terms of particle size effects, related to specific crystallographic sites, whose population varies with the particle size and morpholoy. At so-called "open" sites, a minimum adsorbate-substrate interaction occurs. Furthermore, from comparative EMIRS studies of $0.1 \mathrm{M} \mathrm{CH}_{3} \mathrm{OH}$, chemisorption on model single crystal $\mathrm{Pt}$ faces [2], there is no doubt that the poisoning by $\mathrm{CO}_{\text {ads }}$ species is much less intense on the (111) orientation than on the two other low index planes. More recent experiments carried out on $\mathrm{Pt}(111)$ have even shown that the $\mathrm{CO}_{\mathrm{ad}}$-type poisoning mechanism is no longer consistent when the concentration of methanol in the bulk is decreased to values lower than $10^{-3} \mathrm{M}[27]$.

This is certainly relevant to the enhanced catalytic properties of electrodispersed Pt and its expected structure based upon (111) oriented facets. In conclusion, the use of the electrocatalytic reactions to study electrodispersed Pt electrodes offers a promising means of understanding the influence of particle size and crystalline face distributions in electrocatalysis, a problem which, up to now, has only been tackled empirically, because of the lack of a basis of fundamental physical chemistry [28].

\section{ACKNOWLEDGEMENTS}

Part of the work was financially supported by the Consejo Nacional de Investigaciones Cientificas y Técnicas (CONICET) and the Comision de Investigaciones Cientificas de la Provincia de Buenos Aires. The cooperative work was supported by a Scientific Programme involving the CNRS and the CONICET, to which the authors are indebted.

\section{REFERENCES}

1 S. Juanto, B. Beden, F. Hahn, J.M. Léger and C. Lamy, J. Electroanal. Chem., 237 (1987) 119.

2 B. Beden, S. Juanto, J.M. Léger and C. Lamy, J. Electroanal. Chem., 238 (1987) 323.

3 B. Bittins-Cattaneo, E. Santos, W. Vielstich and U. Linke, Electrochim. Acta, 33 (1988) 1499.

4 B. Beden, F. Hahn, C. Lamy, J.M. Léger, N.R. de Tacconi, R.O. Lezna and A.J. Arvia, J. Electroanal. Chem., 261 (1989) 401. 
5 B. Beden, F. Hahn, C. Lamy, J.M. Léger, C.L. Perdriel, N.R. de Tacconi, R.O. Lezna and A.J. Arvia, J. Electroanal. Chem., to be submitted.

6 W.E. Triaca, T. Kessler, J.C. Canullo and A.J. Arvia, J. Electroanal. Chem., 134 (1987) 1165.

7 A. Bewick and B.S. Pons, in R.J.H. Clark and R.E. Hester (Eds.), Advances in Infrared and Raman Spectroscopy, Vol. 12, Wiley-Heyden, London, 1985, Ch. 1.

8 B. Beden and C. Lamy, in R.J. Gale (Ed.), Spectroelectrochemisty, Theory and Practice, Plenum Press, Ncw York, 1988, Ch. 5, p. 189.

9 B. Beden, F. Hahn, S. Juanto, C. Lamy and J.M. Léger, J. Electroanal. Chem., 225 (1987) 215.

$10 \mathrm{~K}$. Nakamoto, Infrared Spectra of Inorganic and Coordination Compounds, Wiley-Interscience, New York, 1986.

11 B. Beden, A. Bewick, K. Kunimatsu and C. Lamy, J. Electroanal. Chem., 142 (1982) 345.

12 T. Iwasita and W. Vielstich, J. Electroanal. Chem., 250 (1988) 451.

13 K.I. Ota, Y. Nakagawa and M. Takahashi, J. Electroanal. Chem., 179 (1984) 179.

14 El.M. Belgsir, H. Huser, J.M. Léger and C. Lamy, J. Electroanal. Chem., 225 (1987) 281.

15 M. Choy de Martinez, B. Beden, F. Hahn and C. Lamy, J. Electroanal. Chem., 249 (1988) 265.

16 M.L. Marcos, J.M. Vara, J. González-Velasco and A.J. Arvia, J. Electroanal. Chem., 224 (1987) 189.

17 A.M. Castro Luna, M.C. Giordano and A.J. Arvia, J. Electroanal. Chem., 259 (1989) 173.

18 J. Gómez, L. Váquez, A.M. Baró, N. García, C.L. Perdriel, W.E. Triaca and A.J. Arvia, Nature, 323 (1986) 612.

19 L. Vásquez, A. Bartolomé, A.M. Baró, C. Alonso, R.C. Salvarezza and A.J. Arvia, Surf. Sci., in press.

20 J.J. Burton, Cat. Rev. Sci. Eng., 9 (1978) 204.

21 K. Kinoshita, in J.O'M. Bockris, B.E. Conway and R.E. White (Eds.), Modern Aspects of Electrochemistry, Plenum Press, New York and London, 1982, Vol. 14, p. 557.

22 A.C. Chialvo, W.E. Triaca and A.J. Arvia, J. Electroanal. Chem., 146 (1983) 93.

23 M.R. McClellan, J.L. Gland and F.R. McFeely, Surf. Sci., 112 (1981) 63.

24 C. Campbell, G. Ertl, H. Knipers and J. Segner, Surf. Sci., 107 (1981) 207.

25 R.G. Greenler, K.D. Burch, K. Kretzchmar, R. Klanser, A.M. Bradshaw and B.E. Hayden, Surf. Sci., $152(1985) 338$.

26 D.W. Daniel, J. Phys. Chem., 92 (1988) 3891.

27 I. Lopes, B. Beden, F. Hahn, J.M. Léger and C. Lamy, J. Electroanal. Chem., submitted.

28 K. Kinoshita and P. Stonehart, in J.O'M. Bockris and B.E. Conway (Eds.), Modern Aspects of Electrochemistry, Plenum Press, New York and London, 1977, Vol. 12, p. 183. 